\title{
The FEZI Gene Shows No Association to Schizophrenia in Caucasian or African American Populations
}

\author{
Colin A Hodgkinson*,', David Goldman', Francesca Ducci', Pamela DeRosse', Daniel A Caycedo', \\ Emily R Newman', John M Kane ${ }^{2}$, Alec Roy ${ }^{3}$ and Anil K Malhotra ${ }^{2}$ \\ 'Section of Human Neurogenetics, Laboratory of Neurogenetics, National Institute on Alcohol Abuse and Alcoholism, Bethesda, MD, USA; \\ ${ }^{2}$ Psychiatry Research, Hillside Hospital, Glen Oaks, NY, USA; ${ }^{3}$ Psychiatry Service, Department of Veterans Affairs, New Jersey Health System, \\ East Orange, NJ, USA
}

\begin{abstract}
Schizophrenia is a complex psychiatric disorder with both genetic and environmental components and is thought to be in part neurodevelopmental in origin. The DISCI gene has been linked to schizophrenia in two independent Caucasian populations. The DISCI protein interacts with a variety of proteins including FEZI, the mammalian homolog of the Caenorhabditis elegans unc-76 protein, which is involved in axonal outgrowth. Variation at the FEZI gene has been associated with schizophrenia in a large Japanese cohort. In this study, nine SNP markers at the FEZI locus were genotyped in two populations. A North American Caucasian cohort of 212 healthy controls, 178 schizophrenics, 79 bipolar disorder, and 58 with schizoaffective disorder, and an African American cohort of I 33 healthy controls, 162 schizophrenics, and 28 with schizoaffective disorder. No association to schizophrenia, bipolar disorder or schizoaffective disorder was found for any of the nine markers typed in these populations at the allelic or the genotypic level. Additionally no association was found in either population between specific haplotypes and any of the psychiatric disorders. Variation at the FEZI locus does not play a significant role in the etiology of schizophrenia, bipolar disorder or schizoaffective disorder in North American Caucasian or African American populations.

Neuropsychopharmacology (2007) 32, 190-196. doi:10.1038/sj.npp. I30II77; published online 16 August 2006
\end{abstract}

Keywords: schizophrenia; schizoaffective; genetics; association; haplotype; African American

\section{INTRODUCTION}

Schizophrenia (OMIM 181500) is debilitating psychiatric disorder that affects more than 29 million individuals worldwide (Barbato, 1998). It is a heritable disorder with a complex transmission pattern as evidenced from family and twin studies (Berry et al, 2003). The disorder has been linked to multiple chromosomal regions and several findings now appear to have been widely replicated, including Neuregulin, COMT. and DISC1 (Stefansson et al, 2004; Shirts and Nimgaonkar, 2004; Hennah et al 2003; Hodgkinson et al, 2004).

Both Disrupted in Schizophrenia 1 and 2 (DISC1 and DISC2, OMIM 605210, and OMIM 606271) were observed to be disrupted by a balanced $(1 ; 11)(\mathrm{q} 42.1 ; \mathrm{q} 14.3)$ translocation in a large Scottish family displaying a broad spectrum

*Correspondence: Dr CA Hodgkinson, Laboratory of Neurogenetics, National Institute on Alcohol Abuse and Alcoholism, 5625 Fishers Lane, Room 3S32, MSC9412, Rockville, MD 20852, USA, Tel: + I 30 I 443 7633, Fax: + I 30 I 480 2839, E-mail: chodg@mail.nih.go

Received 6 December 2005; revised 22 May 2006; accepted 27 June 2006

Online publication: I I July 2006 at http://www.acnp.org/citations/ Npp07| | 06050722/default.pdf of psychiatric disorders, in particular, schizophrenia and major depression (Millar et al, 2000, 2001; Blackwood et al, 2001). Although analysis of other independent Scottish families with schizophrenia and bipolar disorder failed to show significant association between disease and these two genes (Devon et al, 2001), association to schizophrenia was shown in a Finnish population (Hennah et al, 2003) and to schizophrenia, schizoaffective disorder and bipolar disorder in a North American Caucasian population (Hodgkinson et al, 2004). The region containing the two DISC genes also showed linkage to schizophrenia and schizoaffective disorder in Taiwanese families (Hwu et al, 2003).

The DISC1 gene codes for a large (854 amino acid) protein of unknown function, with no homology to known proteins (Millar et al, 2000). DISC1 has been shown to occupy a variety of subcellular compartments and to exist in multiple isoforms generated by alternative splicing of the mRNA transcript (Millar et al, 2003; Morris et al, 2003; Ozeki et al, 2003; Brandon et al, 2004; James et al, 2004). Two-hybrid experiments in yeast systems have shown the DISC1 protein to interact with a large number of different proteins from a wide variety of different protein (Morris et al, 2003; Ozeki et al, 2003; Brandon et al, 2004; Miyoshi et al, 2004). The DISC2 gene is thought to encode a nontranslated mRNA 
antisense to DISC1, and may have a regulatory function (Millar et al, 2000).

FEZ1 protein (OMIM 604825), was identified as a DISC1 interacting partner in a yeast 2-hybrid screen of an adult human brain library (Miyoshi et al, 2003). FEZ1 is the ortholog of the Caenorhabditis elegans unc-76 gene (Horvitz, 1997). Worms carrying mutations in the unc-76 gene show severe abnormalities in movement and in elongation of axons along other axonal surfaces (but not non-neuronal surfaces) during development. This process, known as fasciculation, enables axons to associate in specific bundles and is likely to play a major role in determination of neural structures.

Association between SNP polymorphisms in the FEZ1 gene and schizophrenia has been shown in a Japanese cohort (Yamada et al, 2004). This association was shown not to have arisen due to population admixture. In this study, we have looked at two ethnically distinct North American populations for association of schizophrenia to the FEZ1 locus. In both of these populations, linkage of the FEZ-interacting partner DISC1 to schizophrenia was observed (Hodgkinson et al, 2004 and unpublished results), data that replicated findings in a Finnish cohort (Hennah et al, 2003).

\section{MATERIALS AND METHODS}

\section{Subject Recruitment and Diagnosis}

Subjects were recruited from the clinical services of the Zücker Hillside Hospital, a division of the North ShoreLong Island Jewish Health System (NSLIJHS), in Glen Oaks, NY, USA, and from the Psychiatry Service, Department of Veterans Affairs, New Jersey Health Care System in East Orange, NJ, USA. These studies were performed in a manner that fully complies with the Code of Ethics of the World Medical Association (Declaration of Helsinki) and was approved by the relevant Institutional Review Boards. After providing written informed consent to participate in the study, each subject was assessed with the Structured Clinical Interview for DSM-IV Axis I Disorders using method previously described (Hodgkinson et al, 2004). The Caucasian sample of 521 individuals was comprised of 212 healthy controls, 178 schizophrenics, 79 bipolar disorder patients, and 58 patients with schizoaffective disorder. The African American sample, totaling 323 individuals, contained 133 healthy controls, 162 diagnosed schizophrenics, and 28 with schizoaffective disorder.

\section{Genotyping}

Nine SNP loci spanning the $61 \mathrm{~kb}$ FEZ1 gene region were genotyped by $5^{\prime}$ exonuclease assay, using the primer-probe sets available as Taqman ${ }^{\circledR}$ Assays-on-Demand (Applied Biosystems, Foster City, CA, USA). Genomic DNA (5 ng) was amplified on a 9700 thermocycler (ABi) using a program with an initial incubation at $95^{\circ} \mathrm{C}$ for $10 \mathrm{~min}$ followed by 40 cycles of $92^{\circ} \mathrm{C}(15 \mathrm{~s})$ and $60^{\circ} \mathrm{C}(1 \mathrm{~min})$. At the end point of amplification, genotypes were discriminated using SDS 2.0 software on an Applied Biosystems 7900 Analyzer. Genotype completion rates for all markers were $\geqslant 98.9 \%$. Genotyping accuracy was assessed by regeno- typing one in six samples, randomly selected, revealing an overall accuracy $>99 \%$. Haplotype block structure was determined using the HAPLOVIEW program (Barrett et al, 2005). Blocks were defined according to the criteria of Gabriel et al (2002) but the criterion for pairwise LD between markers was relaxed from $D^{\prime}>95 \%$ to $D^{\prime}>85 \%$ within a block. Haplotypes were assigned to individuals using PHASE 2.02 (Stephens et al, 2001; Stephens and Donnelly, 2003).

\section{Statistical Methods}

Nonparametric testing for significance values for allelic and genotypic association was performed using a standard $\chi^{2}$-test. Haplotype association was evaluated using the more stringent Fisher Exact Test because observed haplotype frequencies sometimes equaled zero. Deviation from Hardy-Weinberg distribution of alleles was determined using the Haploview program and the $p$-values are shown in Table 1. Logistic regression was used to test for interaction between genotypes for each FEZ1 SNP and DISC1 risk/ protective haplotypes as described in Cordell (2002) and Norton et al (2006). Individuals were assigned a score of 1 , 0.5 , or 0 according to the number of copies of DISC1 haplotypes significantly associated with schizophrenia and/ or schizoaffective disorders in Hodgkinson et al (2004). Analysis were conducted separately for each diagnostic category and for each of the three DISC1 haploblocks previously linked to schizophrenia and/or schizoaffective disorders.

\section{RESULTS}

No FEZ1 SNP showed association to either schizophrenia or schizoaffective disorder in Caucasians (Table 1) or to schizophrenia in African Americans (Table 2), at either the allelic or genotypic level. The markers tested include rs559668 and rs597570, both of which had shown genotypic association in the Japanese study. Also, none of these markers showed association to bipolar disorder in Caucasians. All nine FEZ1 markers are in strong linkage disequilibrium and reside in a single haplotype block (Figure 1). As expected there was increased haplotype diversity in the African American population compared to the Caucasian group. Moreover the minor allele frequencies differed greatly between the populations (Table 3). There was no significant association between schizophrenia and any haplotype in either population (Table 4). Nor was there any association to schizoaffective disorder or bipolar disorder in Caucasians. In the Japanese population, schizophrenia was associated with homozygosity of the A allele at the rs559668 and rs597570 loci. The frequency of these alleles was higher in Caucasians (18\%) and African Americans (29 and 21\%) than in the original Japanese cohort (2\%) and in an American Asian group (2\%). In the Japanese study, association to schizophrenia was found to homozygosity for the minor alleles of the two tightly linked markers which are separated by over $200 \mathrm{~kb}$. In that study, seven affected individuals but no controls were homozygous for the two markers. In our African American cohort, we found nine of 178 diagnosed schizophrenics and 13 of 212 
Table I Allelic and Genotypic Association of FEZI SNPs in Caucasians, Comparing Healthy Controls (HC), Schizophrenics (SZ), Schizoaffective Disorder (SA), and Bipolar Disorder (BP)

\begin{tabular}{|c|c|c|c|c|c|c|c|c|c|c|}
\hline Marker & $\begin{array}{l}\text { NCBI position } \\
\text { (Build 35) }\end{array}$ & Samples & & & $p$-value & & Genotype & & $p$-value & $\begin{array}{c}\text { HW variation } \\
p \text {-value }\end{array}$ \\
\hline \multirow[t]{3}{*}{ rs2702009 } & $|2487005|$ & & C & $\mathrm{T}$ & & $\mathrm{C} / \mathrm{C}$ & $\mathrm{C} / \mathrm{T}$ & $\mathrm{T} / \mathrm{T}$ & & \\
\hline & & $\mathrm{SZ}$ & $256(0.72)$ & $100(0.28)$ & 0.994 & $94(0.53)$ & $68(0.38)$ & $16(0.09)$ & 0.900 & \\
\hline & & SA & $84(0.74)$ & $30(0.26)$ & 0.711 & $31(0.54)$ & $22(0.39)$ & $4(0.07)$ & 0.934 & \\
\hline \multirow[t]{4}{*}{ rs559668 } & 124862986 & & C & $\mathrm{T}$ & & $\mathrm{C} / \mathrm{C}$ & $\mathrm{C} / \mathrm{T}$ & $\mathrm{T} / \mathrm{T}$ & & \\
\hline & & $\mathrm{HC}$ & $77(0.18)$ & $345(0.82)$ & & $8(0.04)$ & $61(0.29)$ & $142(0.67)$ & & 0.901 \\
\hline & & $\mathrm{SZ}$ & $68(0.19)$ & $286(0.8 I)$ & 0.732 & $8(0.05)$ & $52(0.29)$ & $117(0.66)$ & 0.927 & \\
\hline & & SA & $19(0.16)$ & $97(0.84)$ & 0.642 & $0(0.00)$ & $19(0.33)$ & 39 (0.67) & 0.297 & \\
\hline & & $\mathrm{HC}$ & $75(0.18)$ & $345(0.82)$ & & $7(0.03)$ & $61(0.29)$ & $142(0.68)$ & & 1.0 \\
\hline & & $\mathrm{SZ}$ & $69(0.19)$ & $287(0.81)$ & 0.586 & $9(0.05)$ & $51(0.29)$ & I I 8 (0.66) & 0.696 & \\
\hline & & SA & $19(0.16)$ & $97(0.84)$ & 0.711 & $0(0.00)$ & $19(0.33)$ & 39 (0.67) & 0.342 & \\
\hline & & $\mathrm{BP}$ & $25(0.16)$ & I $33(0.84)$ & 0.564 & $2(0.03)$ & $21(0.27)$ & $56(0.7 \mid)$ & 0.848 & \\
\hline \multirow[t]{5}{*}{ rs 10893385} & $|24854| 3 \mid$ & & A & G & & $\mathrm{A} / \mathrm{A}$ & $\mathrm{A} / \mathrm{G}$ & $\mathrm{G} / \mathrm{G}$ & & \\
\hline & & $\mathrm{HC}$ & $222(0.53)$ & $200(0.47)$ & & $57(0.27)$ & $108(0.5 \mathrm{I})$ & $46(0.22)$ & & 0.862 \\
\hline & & $\mathrm{SZ}$ & I $80(0.5 \mid)$ & $174(0.49)$ & 0.625 & $49(0.28)$ & $82(0.46)$ & $46(0.26)$ & 0.551 & \\
\hline & & SA & $65(0.56)$ & $51(0.44)$ & 0.512 & I $8(0.3 \mid)$ & $29(0.50)$ & II (0.19) & 0.799 & \\
\hline & & $\mathrm{BP}$ & $79(0.50)$ & $79(0.50)$ & 0.576 & $22(0.28)$ & $35(0.44)$ & $22(0.28)$ & 0.481 & \\
\hline \multirow[t]{5}{*}{ rs|2223|86 } & 124836849 & & A & G & & $\mathrm{A} / \mathrm{A}$ & $A / G$ & $\mathrm{G} / \mathrm{G}$ & & \\
\hline & & $\mathrm{HC}$ & $179(0.42)$ & $245(0.58)$ & & $37(0.17)$ & $105(0.50)$ & $70(0.33)$ & & 0.575 \\
\hline & & $\mathrm{SZ}$ & I 32 (0.38) & $218(0.62)$ & 0.203 & $27(0.15)$ & $78(0.45)$ & $70(0.40)$ & 0.363 & \\
\hline & & SA & $46(0.40)$ & $70(0.60)$ & 0.620 & $10(0.17)$ & $26(0.45)$ & $22(0.38)$ & 0.767 & \\
\hline & & $\mathrm{BP}$ & $57(0.36)$ & I0I (0.64) & 0.180 & II (0.14) & $35(0.44)$ & $33(0.42)$ & 0.367 & \\
\hline \multirow[t]{5}{*}{ rs224I5I4 } & $12483 \mid 236$ & & C & $\mathrm{T}$ & & $\mathrm{C} / \mathrm{C}$ & $\mathrm{C} / \mathrm{T}$ & $\mathrm{T} / \mathrm{T}$ & & \\
\hline & & $\mathrm{HC}$ & $173(0.4 I)$ & $25 \mid(0.59)$ & & $35(0.17)$ & $103(0.49)$ & $74(0.35)$ & & 0.76 \\
\hline & & $\mathrm{SZ}$ & I 37 (0.38) & $219(0.62)$ & 0.510 & $27(0.15)$ & $83(0.47)$ & $68(0.38)$ & 0.788 & \\
\hline & & SA & $46(0.40)$ & $70(0.60)$ & 0.824 & $10(0.17)$ & $26(0.45)$ & $22(0.38)$ & 0.875 & \\
\hline & & $\mathrm{BP}$ & $58(0.37)$ & $100(0.63)$ & 0.369 & II (0.14) & $36(0.46)$ & $32(0.4 I)$ & 0.654 & \\
\hline \multirow[t]{5}{*}{ rs2907228 } & $12482 \mid 283$ & & A & T & & $A / A$ & $\mathrm{~A} / \mathrm{T}$ & $\mathrm{T} / \mathrm{T}$ & & \\
\hline & & $\mathrm{HC}$ & $372(0.88)$ & $52(0.12)$ & & I6I (0.76) & $50(0.24)$ & I (0.005) & & 0.762 \\
\hline & & $\mathrm{SZ}$ & $305(0.86)$ & $51(0.14)$ & 0.804 & $134(0.77)$ & $37(0.21)$ & $4(0.02)$ & 0.259 & \\
\hline & & SA & $103(0.89)$ & II (0.1 I) & $0.44 I$ & $46(0.8 I)$ & II (0.19) & $0(0.00)$ & 0.765 & \\
\hline & & $\mathrm{BP}$ & I 33 (0.84) & $25(0.16)$ & 0.940 & $59(0.78)$ & $15(0.20)$ & $2(0.02)$ & 0.235 & \\
\hline
\end{tabular}


Table I Continued

\begin{tabular}{|c|c|c|c|c|c|c|c|c|c|c|}
\hline \multirow{2}{*}{$\frac{\text { Marker }}{\text { rs } 10893380}$} & \multirow{2}{*}{$\begin{array}{c}\begin{array}{c}\text { NCBI position } \\
\text { (Build 35) }\end{array} \\
124816884\end{array}$} & \multirow[t]{2}{*}{ Samples } & \multicolumn{2}{|c|}{ Allele } & \multirow[t]{2}{*}{$p$-value } & \multicolumn{3}{|c|}{ Genotype } & \multirow[t]{2}{*}{$p$-value } & \multirow[t]{2}{*}{$\begin{array}{c}\text { HW variation } \\
p \text {-value }\end{array}$} \\
\hline & & & A & G & & $\mathrm{A} / \mathrm{A}$ & $A / G$ & G/G & & \\
\hline & & $\mathrm{sZ}$ & $47(0.13)$ & $309(0.87)$ & 0.536 & $4(0.02)$ & $39(0.22)$ & $135(0.76)$ & 0.450 & \\
\hline & & SA & $10(0.09)$ & $104(0.91)$ & 0.380 & $0(0.00)$ & $10(0.18)$ & $47(0.82)$ & 0.627 & \\
\hline
\end{tabular}

Table 2 Allelic and Genotypic Association of FEZI SNPs in African Americans Comparing Healthy Controls (HC), and Schizophrenics (SZ)

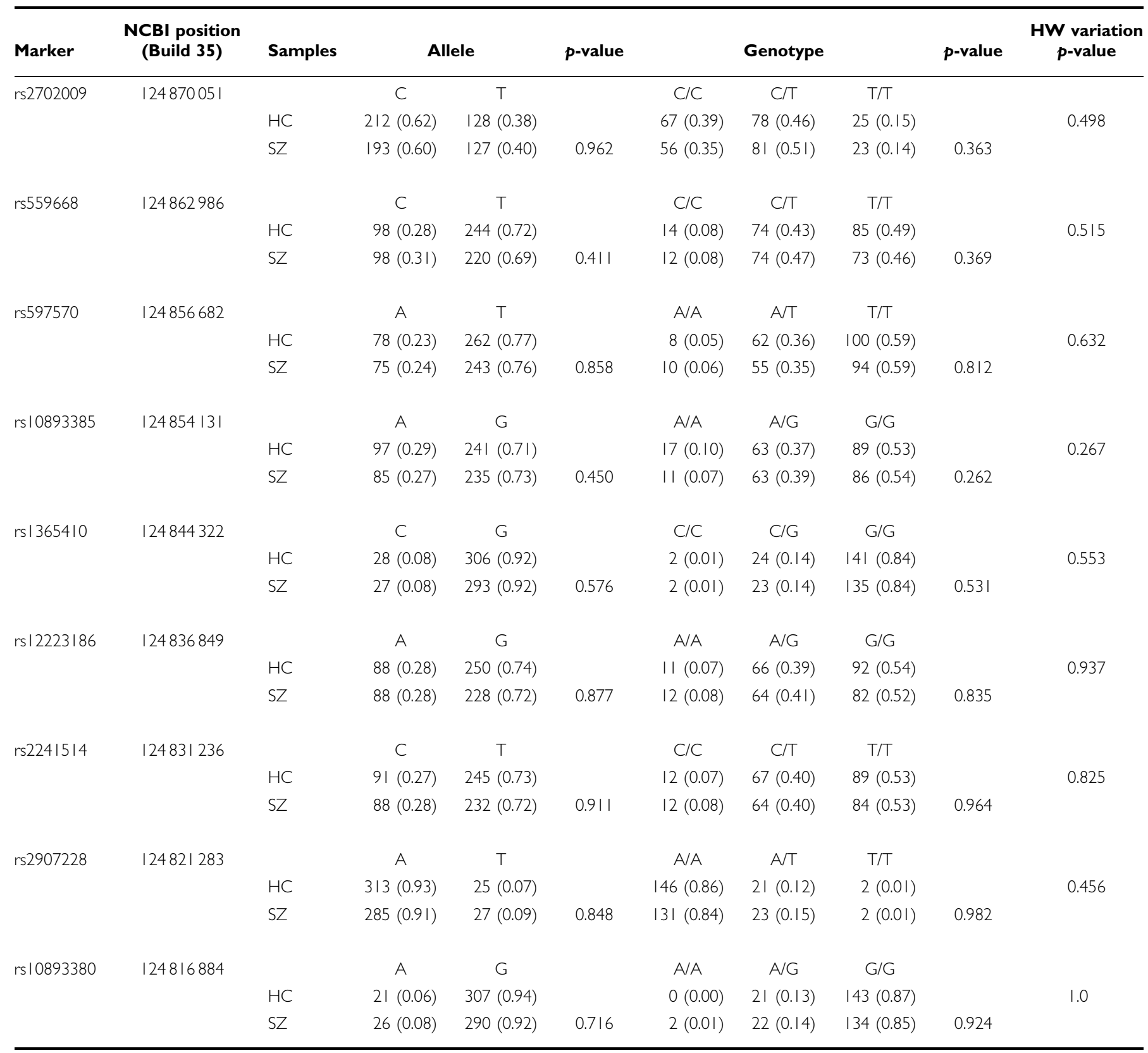

healthy controls homozygous for the same two A alleles. In the Caucasian group, we found eight of 178 diagnosed schizophrenics to be homozygous for the same two A alleles, seven of 212 healthy controls, one of 70 diagnosed with bipolar disorder and 0 of 58 diagnosed with schizoaffective disorder. Thus, we found no increase in homozygosity. Analysis of homozgosity at the diplotype level showed no association in either the Caucasian or 


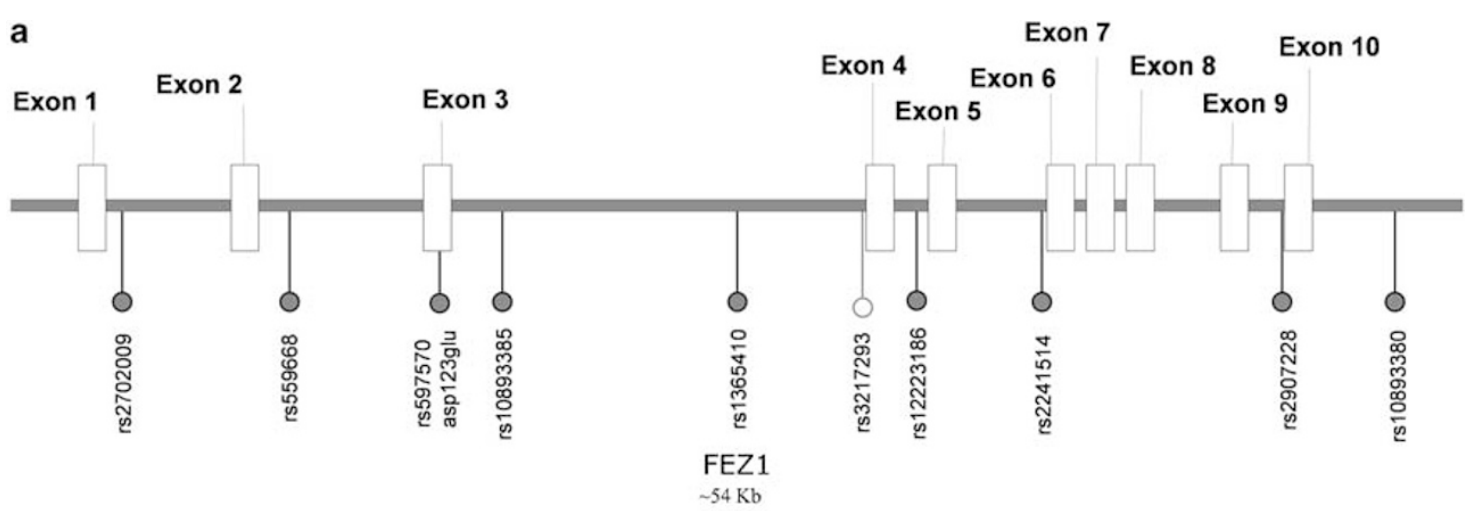

b
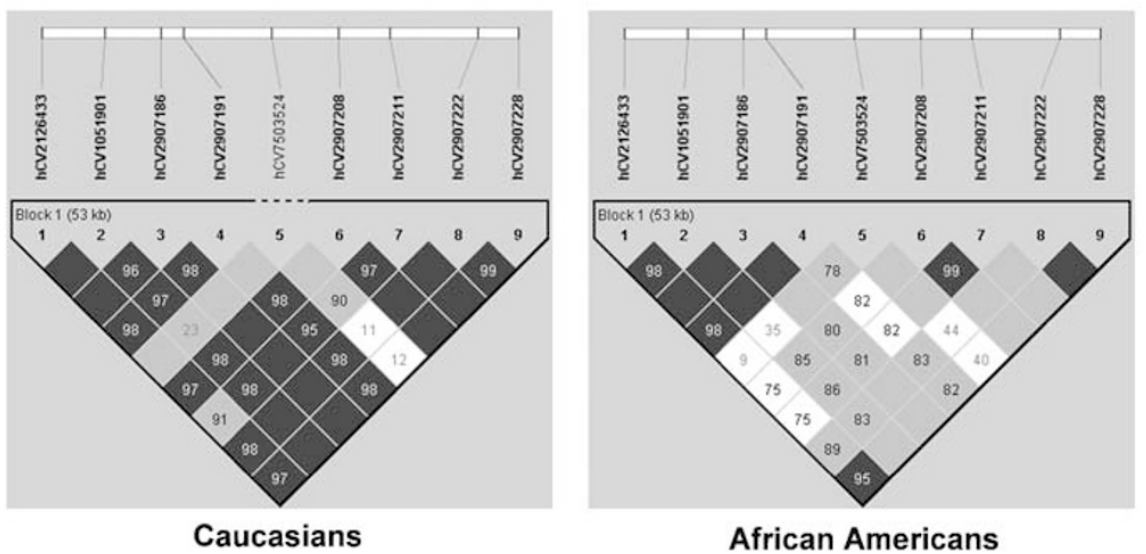

Figure I (a) Diagram of the human FEZI gene showing the relative positions of exons and the SNP markers used (shaded circles). Marker rs32I7293 from Yamada et al (Biol Psychiatry 2004; 56: 683-690.) shown with open circle. (b) Haplotype block structure of the FEZI locus in Caucasians and African Americans.

African American populations by Fisher Exact test (data not shown). Analysis of a small group of African Americans diagnosed with schizoaffective disorder $(n=28)$ did show a genotype association $(p=0.038)$ at marker rs559668 and a haplotype association $(p=0.025)$ for the 112222212 haplotype. Neither of these associations remained significant after correction for multiple testing.

The failure to detect association of schizophrenia to FEZ1 haplotypes is unlikely to arise due to lack of power in the data set. For schizophrenics both the Caucasian and African American datasets have sufficient power to detect significance $(p=0.05)$ for frequency differences of 1.2 at $90 \%$ confidence, and for frequency differences of 1.6 at $99 \%$ confidence. For schizoaffective disorder the Caucasian dataset has sufficient power to detect significance $(p=0.05)$ for frequency differences of 2.1 at $90 \%$ confidence, and of 2.8 at $99 \%$ confidence.

Given the biological evidence of interaction between DISC1 and FEZ1, logistic regression was performed to test whether variation at FEZ1 contributed to the risk of schizophrenia and/or schizoaffective disorders depending on DISC1 disease-associated haplotypes. For schizophrenia no significant interaction was observed for any FEZ1 SNP to DISC1 haplotypes for Haploblocks 1, 2, or 3. Significant $p$-values were obtained for interaction of rs2702009 $(p=0.001)$ and $\operatorname{rs} 10893385(p=0.03)$ with the common protective DISC1 haplotype previously shown to be under represented in Caucasian women with schizoaffective disorder. These data, however, should be treated with extreme caution due to the relatively low number of affected individuals in the analysis $(n=57)$ and the elevated number of statistical tests performed $(n=54)$. Based on these data it appears unlikely that any significant GXG interaction between FEZ1 and DISC1 exists.

\section{DISCUSSION}

An important genetic component in the etiology of schizophrenia is thought to be a neurodevelopmental defect (Lewis and Levitt, 2002) that either occurs in latent form early in development (Marenco and Weinberger, 2000) or at a later stage during brain maturation in adolescence (Feinberg, 1982), the time at which early symptoms begin to appear. FEZ1 when expressed in unc-76 mutant worms can partially rescue the locomotor phenotype suggestive of a shared developmental function (Horvitz, 1997) and suggesting that these sequence-similar proteins are orthologs. Studies in primates and rodents demonstrate that FEZ1 and DISC1 have overlapping spatial and temporal expression patterns (Austin et al, 2004; Honda et al, 2004; Inoue et al, 2004; Schurov et al, 2004). Both proteins are expressed in the pyramidal neurons of the developing hippocampus, the cerebral neocortex and the olfactory bulb. Moreover disruption of the DISC1/FEZ1 interaction inhibits DISC1-stimulated neurite outgrowth in PC12 cells (Miyoshi et al, 2003). Together these data make FEZ1 a compelling candidate gene. Our data, however, indicates no strong role of variation at the FEZ1 locus in schizophrenia in Caucasian 
or African American populations. The asp ${ }^{123}$ residue is conserved between humans and rodents. This residue lies within a region shown to be responsible for the axonal

Table 3 Minor Allele Frequencies in Three North American Populations

Minor allele frequency

\begin{tabular}{cccc}
\cline { 2 - 3 } Marker & $\begin{array}{c}\text { Caucasian } \\
(n=633)\end{array}$ & African American & Asian \\
$(n=428)$ & $(n=44)$
\end{tabular}

rs2702009

$\mathrm{C}>\mathrm{T}$

0.28

0.38

0.43

rs559668

$\mathrm{T}>\mathrm{C}$

0.18

0.29

0.02

rs597570

$\mathrm{T}>\mathrm{A}$

0.18

0.21

0.02

rs 10893385

$A>G$

0.48

0.29 *

0.45

\section{rs 1365410}

G $>C$

0.01

0.08

0.02

$r s / 2223 / 86$
$G>A$

0.39

0.28

0.38

\section{rs22415/4}

$\mathrm{T}>\mathrm{C}$

0.39

0.28

0.35

\section{rs 2907228}

A > T

0.12

0.08

0.36

rs 10893380

G>A

0.12

0.07

0.34 targeting of the unc-76 protein (Horvitz, 1997) and it has been suggested that the glutamate substitution affects the subcellular distribution of the FEZ1 protein (Miyoshi et al, 2003). The asp ${ }^{123}$ glu transition ( $r$ 597970) is a conservative substitution and this residue is not conserved in either Gallus gallus (his) or in C. elegans (thr) suggesting that it is unlikely to have a functional role in axonal targeting of the mature FEZ1 protein. Our findings do not exclude the possibility that a functional polymorphism unique to the Japanese population exists in strong LD with rs559668 and rs597570 which when present in the homozygous state results in an increased predisposition to the development of schizophrenia. Sequencing of the Japanese schizophrenics homozygous for the two associated markers may identify the relevant polymorphism, which could lie either in the axonal targeting $\mathrm{N}$-terminus, or the DISC1-interacting C-terminus of FEZ1.

Although association has been shown between schizophrenia and DISC1 in two independent Caucasian populations including the Caucasians studied here, no association was found in a case/control study involving $\geqslant 1000$ individuals from Japan (Kockelkorn et al, 2004). This suggests that variation at the DISC1 locus may play no role in the etiology of schizophrenia in the Japanese population. It would, therefore, be hardly surprising that the converse were found for other loci. Schizophrenia and schizophrenia spectrum disorders are complex diseases showing variability in many features in terms of symptoms, age of onset and genetics. Certainly the clinical heterogeneity coupled to the number and diversity of genes reported to be associated with schizophrenia might support the idea that the clinical entity known as schizophrenia could arise from dysregulation of different molecular pathways or by disruption of a common pathway at multiple different points.

\section{ACKNOWLEDGEMENTS}

This project was supported by grants from the National Institutes of Mental Health (K23MH001760), NARSAD, and the Stanley Medical Research Institute to AKM and support from the National Institute on Alcohol Abuse and Alcoholism Intramural Research Program. The authors also

Table 4 Haplotype Associations in African American and Caucasians Comparing Schizophrenics (SZ), Schizoaffective Disorder (SA), and Bipolar Disorder (BP)

\begin{tabular}{|c|c|c|c|c|c|c|c|c|c|c|c|}
\hline \multirow[b]{2}{*}{ Haplotype } & \multicolumn{7}{|c|}{ Caucasians } & \multicolumn{4}{|c|}{ African Americans } \\
\hline & $\begin{array}{l}\text { Controls } \\
(n=212)\end{array}$ & $\begin{array}{c}S Z \\
(n=178)\end{array}$ & $p$-value & $\begin{array}{c}\text { SA } \\
(n=178)\end{array}$ & $p$-value & $\begin{array}{c}\text { BP } \\
(n=79)\end{array}$ & $p$-value & $\begin{array}{l}\text { Controls } \\
(n=166)\end{array}$ & $\begin{array}{c}\text { SZ } \\
(n=161)\end{array}$ & $p$-value & Haplotype \\
\hline 111222212 & $73(0.17)$ & $67(0.19)$ & 0.575 & $19(0.16)$ & 0.890 & $24(0.15)$ & 0.618 & $73(0.22)$ & $73(0.23)$ & 0.391 & 111222212 \\
\hline 122122212 & $46(0.11)$ & $46(0.13)$ & 0.375 & $19(0.16)$ & 0.109 & $23(0.15)$ & 0.248 & $18(0.05)$ & $8(0.02)$ & 0.161 & 122122212 \\
\hline 222222221 & $52(0.12)$ & $45(0.13)$ & 0.913 & || (0.09) & 0.514 & $19(0.12)$ & 0.999 & $14(0.04)$ & $16(0.05)$ & 0.855 & 222222221 \\
\hline 112222212 & - & - & - & - & - & - & - & $8(0.02)$ & $8(0.02)$ & 0.999 & |12222212 \\
\hline 112212212 & - & - & - & - & - & - & - & $15(0.04)$ & $13(0.04)$ & 0.878 & 112212212 \\
\hline 122222212 & - & - & - & - & - & - & - & $16(0.05)$ & II (0.03) & 0.999 & 122222212 \\
\hline $2222 \mid 2221$ & - & - & - & - & - & - & - & II (0.03) & $10(0.03)$ & 0.673 & 222212221 \\
\hline
\end{tabular}


wish to acknowledge the effort of all of the patients and staff at the Zucker Hillside Hospital and the Psychiatry Service, Department of Veterans Affairs, New Jersey Health System who participated in this study.

\section{REFERENCES}

Austin CP, Ky B, Ma L, Morris JA, Shughrue PJ (2004). Expression of disrupted-in-Schizophrenia-1, a schizophrenia-associated gene, is prominent in the mouse hippocampus throughout brain development. Neuroscience 124: 3-10.

Barbato A (1998). Schizophrenia and Public Health. http:// www.who.int/mental_health/media/en/55.pdf.

Barrett JC, Fry B, Maller J, Daly MJ (2005). Haploview: analysis and visualization of $\mathrm{LD}$ and haplotype maps. Bioinformatics 21: 263-265.

Berry N, Jobanputra V, Pal H (2003). Molecular genetics of schizophrenia: a critical review. J Psychiatry Neurosci 28: 415-429.

Blackwood DH, Fordyce A, Walker MT, St Clair DM, Porteous DJ, Muir WJ (2001). Schizophrenia and affective disorderscosegregation with a translocation at chromosome1q42 that directly disrupts brain-expressed genes: clinical and P300 findings in a family. Am J Hum Genet 69: 428-433.

Brandon NJ, Handford EJ, Schurov I, Rain JC, Pelling M, DuranJimeniz B. et al (2004). Disrupted in Schizophrenia 1 and Nudel form a neurodevelopmentally regulated protein complex: implications for schizophrenia and other major neurological disorders. Mol Cell Neurosci 25: 42-45.

Cordell HG (2002). Epistasis: what it means, what it doesn't mean, and statistical methods to detect it in humans. Hum Mol Genet 11: 2463-2468.

Devon RS, Anderson S, Teague PW, Burgess P, Kipari TM, Semple CA et al (2001). Identification of polymorphisms within disrupted in Schizophrenia 1 and disrupted in Schizophrenia 2 , and an investigation of their association with schizophrenia and bipolar affective disorder. Psychiatr Genet 11: 71-78.

Feinberg I (1982). Schizophrenia: caused by a fault in programmed synaptic elimination during adolescence? J Psychiatr Res 17: 319-334.

Gabriel SB, Schaffner SF, Nguyen H, Moore JM, Roy J, Blumenstiel $B$ et al (2002). The structure of haplotype blocks in the human genome. Science 296: 2225-2229.

Hennah W, Varilo T, Kestilä M, Paunio T, Arajärvi R, Haukka J et al (2003). Haplotype transmission analysis provides evidence of association for DISC1 to schizophrenia and suggests sexdependent effects. Hum Mol Genet 12: 3151-3159.

Hodgkinson CA, Goldman D, Jaeger J, Persaud S, Kane JM, Lipsky $\mathrm{RH}$ et al (2004). Disrupted in schizophrenia 1 (DISC1): association with schizophrenia, schizoaffective disorder, and bipolar disorder. Am J Hum Genet 75: 862-872.

Honda A, Miyoshi K, Baba K, Taniguchi M, Koyama Y, Kuroda S et al (2004). Expression of fasciculation and elongation protein zeta-1 (FEZ1) in the developing rat brain. Brain Res Mol Brain Res 122: 89-92.

Horvitz HR (1997). The Caenorhabditis elegans gene unc-76 and its human homolgos define a new family involved in axonal outgrowth and fasciculation. Proc Nat Acad Sci USA 94: 3414-3419.

Hwu HG, Liu CM, Fann CS, Ou-Yang WC, Lee SF (2003). Linkage of schizophrenia with chromosome 1q loci in Taiwanese families. Mol Psychiatry 8: 445-452.

Inoue $\mathrm{K}$, Terashima $\mathrm{T}$, Nishikawa $\mathrm{T}$, Takumi $\mathrm{T}$ (2004). Fez1 is layer-specifically expressed in the adult mouse neocortex. Eur $J$ Neurosci 20: 2909-2916.
James R, Adams RR, Christie S, Buchanan SR, Porteous DJ, Millar JK (2004). Disrupted in Schizophrenia 1 (DISC1) is a multicompartmentalized protein that predominantly localizes to mitochondria. Mol Cell Neurosci 26: 112-122.

Kockelkorn TT, Arai M, Matsumoto H, Fukuda N, Yamada K, Minabe $\mathrm{Y}$ et al (2004). Association study of polymorphisms in the $5^{\prime}$ upstream region of human DISC1 gene with schizophrenia. Neurosci Lett 368: 41-45.

Lewis DA, Levitt P (2002). Schizophrenia as a disorder of neurodevelopment. Annu Rev Neurosci 25: 409-432.

Marenco S, Weinberger DR (2000). The neurodevelopmental hypothesis of schizophrenia: following a trail of evidence from cradle to grave. Dev Psychopathol 12: 501-527.

Millar JK, Christie S, Anderson S, Lawson D, Hsiao-Wei Loh D, Devon RS et al (2001). Genomic structure and localisation within a linkage hotspot of Disrupted In Schizophrenia 1, a gene disrupted by a translocation segregating with schizophrenia. $\mathrm{Mol}$ Psychiatry 6: 173-178.

Millar JK, Christie S, Porteous DJ (2003). Yeast two-hybrid screens implicate DISC1 in brain development and function. Biochem Biophys Res Commun 311: 1019-1025.

Millar JK, Wilson-Annan JC, Anderson S, Christie S, Taylor MS, Semple CA et al (2000). Disruption of two novel genes by a translocation co-segregating with schizophrenia. Hum Mol Genet 9: 1415-1423.

Miyoshi K, Asanuma M, Miyazaki I, Diaz-Corrales FJ, Katayama T, Tohyama M et al (2004). DISC1 localizes to the centrosome by binding to kendrin. Biochem Biophysl Res Commun 317: 11951199.

Miyoshi K, Honda A, Baba K, Taniguchi M, Oono K, Fujita T et al (2003). Disrupted-In-Schizophrenia 1, a candidate gene for schizophrenia, participates in neurite outgrowth. Mol Psychiatry 8: 685-694.

Morris JA, Kandpal G, Ma L, Austin CP (2003). DISC1 (DisruptedIn-Schizophrenia 1) is a centrosome-associated protein that interacts with MAP1A, MIPT3, ATF4/5 and NUDEL: regulation and loss of interaction with mutation. Hum Mol Genet 12: 15911608.

Norton N, Moskvina V, Morris DW, Bray NJ, Zammit S, Williams $\mathrm{NM}$ et al (2006). Evidence that interaction between neuregulin 1 and its receptor erbB4 increases susceptibility to schizophrenia. Am J Med Genet B Neuropsychiatr Genet 141: 96-101.

Ozeki Y, Tomoda T, Kleiderlein J, Kamiya A, Bord L, Fujii K et al (2003). Disrupted-in-Schizophrenia-1 (DISC-1): mutant truncation prevents binding to NudE-like (NUDEL) and inhibits neurite outgrowth. Proc Natl Acad Sci USA 100: 289-294.

Schurov IL, Handford EJ, Brandon NJ, Whiting PJ (2004). Expression of disrupted in schizophrenia 1 (DISC1) protein in the adult and developing mouse brain indicates its role in neurodevelopment. Mol Psychiatry 9: 1100-1110.

Shirts BH, Nimgaonkar V (2004). The genes for schizophrenia: finally a breakthrough? Curr Psychiatry Rep 6: 303-312.

Stefansson H, Steinthorsdottir V, Thorgeirsson TE, Gulcher JR, Stefansson K (2004). Neuregulin 1 and schizophrenia. Ann Med 36: $62-71$.

Stephens M, Donnelly P (2003). A comparison of Bayesian methods for haplotype reconstruction from population genotype data. Am J Hum Genet 73: 1162-1169.

Stephens M, Smith N, Donnelly P (2001). A new statistical method for haplotype reconstruction from population data. Am J Hum Genet 68: 978-989.

Yamada K, Nakamura K, Minabe Y, Iwayama-Shigeno Y, Takao H, Toyota $\mathrm{T}$ et al (2004). Association analysis of FEZ1 variants with schizophrenia in Japanese cohorts. Biol Psychiatry 56: 683-690. 